\title{
Hydration of hydraulic cements based on oyster shell co-products
}

\author{
ALEXANDRA BOURDOT ${ }^{1}$, TULIO HONORIO ${ }^{1}$, MAROUA \\ MAAROUFI $^{1}$, NASSIM SEBAIBI ${ }^{2}$ AND RACHID \\ BENNACER $^{1}$ \\ ${ }^{1}$ Université Paris-Saclay, ENS Paris-Saclay, CNRS \\ ${ }^{2}$ COMUE Normandie Université - ESITC Caen \\ Presenting Author: alexandra.bourdot@ens-paris-saclay.fr
}

Much research effort has been devoted to reducing the amount of cement in construction materials since cement production is directly associated with $\mathrm{CO}_{2}$ emission and energy consumption. The adoption of local solutions to replace cement, especially when the incorporation of by-products and wastes is possible, is one of the interesting alternatives for reducing the impact of using cement-based materials. Oyster shell co-products are available in large quantities in coastal regions [1] and are generally landfilled without any re-use value. These calcareous co-products could be used as fillers or aggregates in cementbased materials. Here, we propose to investigate the effect of using oyster shell powder as a filler on the hydration of cement using isothermal calorimetry tests. Property development in cement-based materials is directly related to hydration evolution, therefore any changes promoted by these calcareous materials on the hydration may impact the properties in the cement-based materials produced with these co-products. Three pastes are characterized to investigate reaction kinetics, heat flow, and the impact of the absorption water on the hydration of the binder. The pastes have: i) a water to binder ratio of 0.5 ; ii) a water to cement ratio of 0.5 and iii) a water to cement ratio of 0.5 to which was added the water of absorption of the aggregates at 24 hours, necessary for the formulation in order to have the effective water for the hydration of the cement. Some results obtained show an effect of the shell powders on the hydration of Portland cement with an acceleration without modification of the induction period. The results tend also to show that oyster shell co-products have an impact with a similar effect to that observed with limestone fillers.

[1] K. H. Mo, U. J. Alengaram, M. Z. Jumaat, S. C. Lee, W. I. Goh, and C. W. Yuen, "Recycling of seashell waste in concrete: A review," Constr. Build. Mater., vol. 162, pp. 751-764, 2018, doi: 10.1016/j.conbuildmat.2017.12.009.

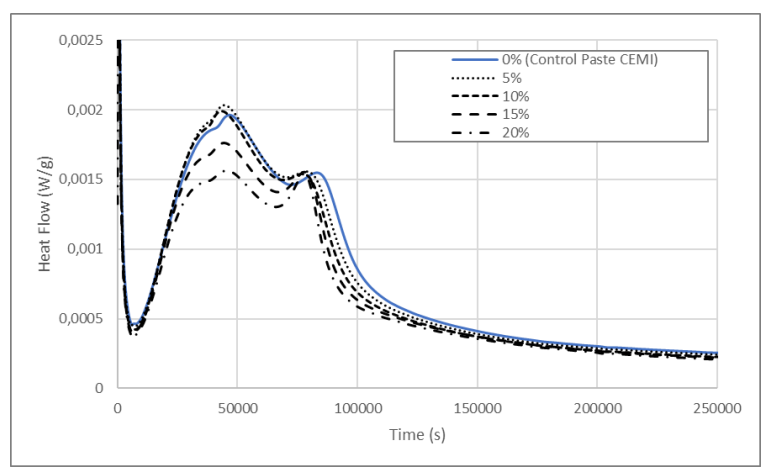

